\title{
Synchronization in ecological networks: A byproduct of Darwinian evolution?
}

Fabio Dercole (dercole@elet.polimi.it)

Daniele Loiacono (loiacono@elet.polimi.it)

Sergio Rinaldi (sergio.rinaldi@polimi.it)

Approved by

Ulf Dieckmann

Program Leader, Evolution and Ecology Program

December 2006 


\section{IIASA STUDIES IN ADAPTIVE DYNAMICS No. 124}

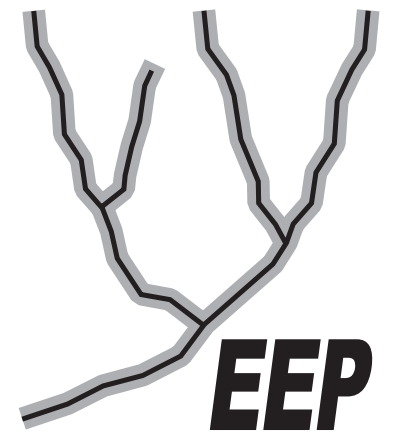

The Evolution and Ecology Program at IIASA fosters the development of new mathematical and conceptual techniques for understanding the evolution of complex adaptive systems.

Focusing on these long-term implications of adaptive processes in systems of limited growth, the Evolution and Ecology Program brings together scientists and institutions from around the world with IIASA acting as the central node.

Scientific progress within the network is collected in the IIASA Studies in Adaptive Dynamics series.
No. 1 Metz JAJ, Geritz SAH, Meszéna G, Jacobs FJA, van Heerwaarden JS: Adaptive Dynamics: A Geometrical Study of the Consequences of Nearly Faithful Reproduction. IIASA Working Paper WP-95-099 (1995). van Strien SJ, Verduyn Lunel SM (eds): Stochastic and Spatial Structures of Dynamical Systems, Proceedings of the Royal Dutch Academy of Science (KNAW Verhandelingen), North Holland, Amsterdam, pp. 183-231 (1996).

No. 2 Dieckmann U, Law R: The Dynamical Theory of Coevolution: A Derivation from Stochastic Ecological Processes. IIASA Working Paper WP-96-001 (1996). Journal of Mathematical Biology 34:579-612 (1996).

No. 3 Dieckmann U, Marrow P, Law R: Evolutionary Cycling of Predator-PreyInteractions: Population Dynamics and the Red Queen. IIASA Preprint (1995). Journal of Theoretical Biology 176:91-102 (1995).

No. 4 Marrow P, Dieckmann U, Law R: Evolutionary Dynamics of Predator-Prey Systems: An Ecological Perspective. IIASA Working Paper WP-96-002 (1996). Journal of Mathematical Biology 34:556-578 (1996).

No. 5 Law R, Marrow P, Dieckmann U: On Evolution under Asymmetric Competition. IIASA Working Paper WP-96-003 (1996). Evolutionary Ecology 11:485-501 (1997).

No. 6 Metz JAJ, Mylius SD, Diekmann O: When Does Evolution Optimize? On the Relation Between Types of Density Dependence and Evolutionarily Stable Life History Parameters. IIASA Working Paper WP-96-004 (1996).

No. 7 Ferrière R, Gatto M: Lyapunov Exponents and the Mathematics of Invasion in Oscillatory or Chaotic Populations. Theoretical Population Biology 48:126-171 (1995).

No. 8 Ferrière R, Fox GA: Chaos and Evolution. IIASA Preprint (1996). Trends in Ecology and Evolution 10:480485 (1995).

No. 9 Ferrière R, Michod RE: The Evolution of Cooperation in Spatially Heterogeneous Populations. IIASA Working Paper WP-96-029 (1996). The American Naturalist 147:692717 (1996).

No. 10 van Dooren TJM, Metz JAJ: Delayed Maturation in Temporally Structured Populations with Non-Equilibrium Dynamics. IIASA Working Paper WP-96-070 (1996). Journal of Evolutionary Biology 11:41-62 (1998).
No. 11 Geritz SAH, Metz JAJ, Kisdi É, Meszéna G: The Dynamics of Adaptation and Evolutionary Branching. IIASA Working Paper WP-96-077 (1996). Physical Review Letters 78:2024-2027 (1997).

No. 12 Geritz SAH, Kisdi É, Meszéna G, Metz JAJ: Evolutionary Singular Strategies and the Adaptive Growth and Branching of the Evolutionary Tree. IIASA Working Paper WP-96-114 (1996). Evolutionary Ecology 12:35-57 (1998).

No. 13 Heino M, Metz JAJ, Kaitala V: Evolution of Mixed Maturation Strategies in Semelparous Life-Histories: The Crucial Role of Dimensionality of Feedback Environment. IIASA Working Paper WP-96-126 (1996). Philosophical Transactions of the Royal Society of London Series B 352:1647-1655 (1997).

No. 14 Dieckmann U: Can Adaptive Dynamics Invade? IIASA Working Paper WP-96-152 (1996). Trends in Ecology and Evolution 12:128-131 (1997).

No. 15 Meszéna G, Czibula I, Geritz SAH: Adaptive Dynamics in a 2-Patch Environment: A Simple Model for Allopatric and Parapatric Speciation. IIASA Interim Report IR-97-001 (1997). Journal of Biological Systems 5:265-284 (1997).

No. 16 Heino M, Metz JAJ, Kaitala V: The Enigma of Frequency-Dependent Selection. IIASA Interim Report IR97-061 (1997). Trends in Ecology and Evolution 13:367-370 (1998).

No. 17 Heino M: Management of Evolving Fish Stocks. IIASA Interim Report IR-97-062 (1997). Canadian Journal of Fisheries and Aquatic Sciences 55:1971-1982 (1998).

No. 18 Heino M: Evolution of Mixed Reproductive Strategies in Simple Life-History Models. IIASA Interim Report IR-97063 (1997).

No. 19 Geritz SAH, van der Meijden E, Metz JAJ: Evolutionary Dynamics of Seed Size and Seedling Competitive Ability. IIASA Interim Report IR-97-071 (1997). Theoretical Population Biology 55:324-343 (1999).

No. 20 Galis F, Metz JAJ: Why Are There So Many Cichlid Species? On the Interplay of Speciation and Adaptive Radiation. IIASA Interim Report IR-97-072 (1997). Trends in Ecology and Evolution 13:1-2 (1998). 
No. 21 Boerlijst MC, Nowak MA, Sigmund K: Equal Pay for all Prisoners/ The Logic of Contrition. IIASA Interim Report IR-97-073 (1997). American Mathematical Society Monthly 104:303-307 (1997). Journal of Theoretical Biology 185:281-293 (1997).

No. 22 Law R, Dieckmann U: Symbiosis Without Mutualism and the Merger of Lineages in Evolution. IIASA Interim Report IR-97-074 (1997). Proceedings of the Royal Society of London Series B 265:1245-1253 (1998).

No. 23 Klinkhamer PGL, de Jong TJ, Metz JAJ: Sex and Size in Cosexual Plants. IIASA Interim Report IR-97-078 (1997). Trends in Ecology and Evolution 12:260-265 (1997).

No. 24 Fontana W, Schuster P: Shaping Space: The Possible and the Attainable in RNA Genotype-Phenotype Mapping. IIASA Interim Report IR-98-004 (1998). Journal of Theoretical Biology 194:491-515 (1998).

No. 25 Kisdi É, Geritz SAH: Adaptive Dynamics in Allele Space: Evolution of Genetic Polymorphism by Small Mutations in a Heterogeneous Environment. IIASA Interim Report IR-98-038 (1998). Evolution 53:993-1008 (1999).

No. 26 Fontana W, Schuster P: Continuity in Evolution: On the Nature of Transitions. IIASA Interim Report IR-98-039 (1998). Science 280:1451-1455 (1998).

No. 27 Nowak MA, Sigmund K: Evolution of Indirect Reciprocity by Image Scoring/ The Dynamics of Indirect Reciprocity. IIASA Interim Report IR-98-040 (1998). Nature 393:573-577 (1998). Journal of Theoretical Biology 194:561574 (1998).

No. 28 Kisdi É: Evolutionary Branching Under Asymmetric Competition. IIASA Interim Report IR-98-045 (1998). Journal of Theoretical Biology 197:149-162 (1999).

No. 29 Berger U: Best Response Adaptation for Role Games. IIASA Interim Report IR-98-086 (1998).

No. 30 van Dooren TJM: The Evolutionary Ecology of Dominance-Recessivity. IIASA Interim Report IR-98-096 (1998). Journal of Theoretical Biology 198:519-532 (1999).

No. 31 Dieckmann U, O'Hara B, Weisser W: The Evolutionary Ecology of Dispersal. IIASA Interim Report IR-98-108 (1998). Trends in Ecology and Evolution 14:88-90 (1999).

No. 32 Sigmund K: Complex Adaptive Systems and the Evolution of Reciprocation. IIASA Interim Report IR-98-100 (1998). Ecosystems 1:444-448 (1998).

No. 33 Posch M, Pichler A, Sigmund K: The Efficiency of Adapting Aspiration Levels. IIASA Interim Report IR-98103 (1998). Proceedings of the Royal Society London Series B 266:1427-1435 (1999).

No. 34 Mathias A, Kisdi É: Evolutionary Branching and Coexistence of Germination Strategies. IIASA Interim Report IR-99-014 (1999).

No. 35 Dieckmann U, Doebeli M: On the Origin of Species by Sympatric Speciation. IIASA Interim Report IR-99-013 (1999). Nature 400:354-357 (1999).

No. 36 Metz JAJ, Gyllenberg M: How Should We Define Fitness in Structured Metapopulation Models? Including an Application to the Calculation of Evolutionarily Stable Dispersal Strategies. IIASA Interim Report IR-99-019 (1999). Proceedings of the Royal Society of London Series B 268:499508 (2001)
No. 37 Gyllenberg M, Metz JAJ: On Fitness in Structured Metapopulations. IIASA Interim Report IR-99-037 (1999). Journal of Mathematical Biology 43:545-560 (2001).

No. 38 Meszéna G, Metz JAJ: Species Diversity and Population Regulation: The Importance of Environmental Feedback Dimensionality. IIASA Interim Report IR-99-045 (1999).

No. 39 Kisdi É, Geritz SAH: Evolutionary Branching and Sympatric Speciation in Diploid Populations. IIASA Interim Report IR-99-048 (1999).

No. 40 Ylikarjula J, Heino M, Dieckmann U: Ecology and Adaptation of Stunted Growth in Fish. IIASA Interim Report IR-99-050 (1999). Evolutionary Ecology 13:433-453 (1999).

No. 41 Nowak MA, Sigmund K: Games on Grids. IIASA Interim Report IR-99-038 (1999). Dieckmann U, Law R, Metz JAJ (eds): The Geometry of Ecological Interactions: Simplifying Spatial Complexity, Cambridge University Press, Cambridge, UK, pp. 135-150 (2000).

No. 42 Ferrière R, Michod RE: Wave Patterns in Spatial Games and the Evolution of Cooperation. IIASA Interim Report IR-99-041 (1999). Dieckmann U, Law R, Metz JAJ (eds): The Geometry of Ecological Interactions: Simplifying Spatial Complexity, Cambridge University Press, Cambridge, UK, pp. 318-332 (2000).

No. 43 Kisdi É, Jacobs FJA, Geritz SAH: Red Queen Evolution by Cycles of Evolutionary Branching and Extinction. IIASA Interim Report IR-00-030 (2000). Selection 2:161$176(2001)$.

No. 44 Meszéna G, Kisdi É, Dieckmann U, Geritz SAH, Metz JAJ: Evolutionary Optimisation Models and Matrix Games in the Unified Perspective of Adaptive Dynamics. IIASA Interim Report IR-00-039 (2000). Selection 2:193-210 (2001).

No. 45 Parvinen K, Dieckmann U, Gyllenberg M, Metz JAJ: Evolution of Dispersal in Metapopulations with Local Density Dependence and Demographic Stochasticity. IIASA Interim Report IR-00-035 (2000). Journal of Evolutionary Biology 16:143-153 (2003).

No. 46 Doebeli M, Dieckmann U: Evolutionary Branching and Sympatric Speciation Caused by Different Types of Ecological Interactions. IIASA Interim Report IR-00-040 (2000). The American Naturalist 156:S77-S101 (2000).

No. 47 Heino M, Hanski I: Evolution of Migration Rate in a Spatially Realistic Metapopulation Model. IIASA Interim Report IR-00-044 (2000). The American Naturalist 157:495$511(2001)$.

No. 48 Gyllenberg M, Parvinen K, Dieckmann U: Evolutionary Suicide and Evolution of Dispersal in Structured Metapopulations. IIASA Interim Report IR-00-056 (2000). Journal of Mathematical Biology 45:79-105 (2002).

No. 49 van Dooren TJM: The Evolutionary Dynamics of Direct Phenotypic Overdominance: Emergence Possible, Loss Probable. IIASA Interim Report IR-00-048 (2000). Evolution 54:1899-1914 (2000).

No. 50 Nowak MA, Page KM, Sigmund K: Fairness Versus Reason in the Ultimatum Game. IIASA Interim Report IR00-57 (2000). Science 289:1773-1775 (2000).

No. 51 de Feo O, Ferrière R: Bifurcation Analysis of Population Invasion: On-Off Intermittency and Basin Riddling. IIASA Interim Report IR-00-074 (2000). International Journal of Bifurcation and Chaos 10:443-452 (2000). 
No. 52 Heino M, Laaka-Lindberg S: Clonal Dynamics and Evolution of Dormancy in the Leafy Hepatic Lophozia Silvicola. IIASA Interim Report IR-01-018 (2001). Oikos 94:525-532 (2001).

No. 53 Sigmund K, Hauert C, Nowak MA: Reward and Punishment in Minigames. IIASA Interim Report IR-01-031 (2001). Proceedings of the National Academy of Sciences of the USA 98:10757-10762 (2001).

No. 54 Hauert C, De Monte S, Sigmund K, Hofbauer J: Oscillations in Optional Public Good Games. IIASA Interim Report IR-01-036 (2001).

No. 55 Ferrière R, Le Galliard J: Invasion Fitness and Adaptive Dynamics in Spatial Population Models. IIASA Interim Report IR-01-043 (2001). Clobert J, Dhondt A, Danchin E, Nichols J (eds): Dispersal, Oxford University Press, pp. 57-79 (2001).

No. 56 de Mazancourt C, Loreau M, Dieckmann U: Can the Evolution of Plant Defense Lead to Plant-Herbivore Mutualism? IIASA Interim Report IR-01-053 (2001). The American Naturalist 158:109-123 (2001).

No. 57 Claessen D, Dieckmann U: Ontogenetic Niche Shifts and Evolutionary Branching in Size-Structured Populations. IIASA Interim Report IR-01-056 (2001). Evolutionary Ecology Research 4:189-217 (2002).

No. 58 Brandt H: Correlation Analysis of Fitness Landscapes. IIASA Interim Report IR-01-058 (2001).

No. 59 Dieckmann U: Adaptive Dynamics of Pathogen-Host Interacations. IIASA Interim Report IR-02-007 (2002). Dieckmann U, Metz JAJ, Sabelis MW, Sigmund K (eds): Adaptive Dynamics of Infectious Diseases: In Pursuit of Virulence Management, Cambridge University Press, Cambridge, UK, pp. 39-59 (2002).

No. 60 Nowak MA, Sigmund K: Super- and Coinfection: The Two Extremes. IIASA Interim Report IR-02-008 (2002). Dieckmann U, Metz JAJ, Sabelis MW, Sigmund K (eds): Adaptive Dynamics of Infectious Diseases: In Pursuit of Virulence Management, Cambridge University Press, Cambridge, UK, pp. 124-137 (2002).

No. 61 Sabelis MW, Metz JAJ: Evolution Management: Taking Stock - Relating Theory to Experiment. IIASA Interim Report IR-02-009 (2002). Dieckmann U, Metz JAJ, Sabelis MW, Sigmund K (eds): Adaptive Dynamics of Infectious Diseases: In Pursuit of Virulence Management, Cambridge University Press, Cambridge, UK, pp. 379-398 (2002).

No. 62 Cheptou P, Dieckmann U: The Evolution of SelfFertilization in Density-Regulated Populations . IIASA Interim Report IR-02-024 (2002). Proceedings of the Royal Society of London Series B 269:1177-1186(2002).

No. 63 Bürger R: Additive Genetic Variation Under Intraspecific Competition and Stabilizing Selection: A Two-Locus Study. IIASA Interim Report IR-02-013 (2002). Theoretical Population Biology 61:197-213 (2002).

No. 64 Hauert C, De Monte S, Hofbauer J, Sigmund K: Volunteering as Red Queen Mechanism for Co-operation in Public Goods Games. IIASA Interim Report IR-02-041 (2002). Science 296:1129-1132 (2002).

No. 65 Dercole F, Ferrière R, Rinaldi S: Ecological Bistability and Evolutionary Reversals under Asymmetrical Competition. IIASA Interim Report IR-02-053 (2002). Evolution 56:1081-1090 (2002).
No. 66 Dercole F, Rinaldi S: Evolution of Cannibalistic Traits: Scenarios Derived from Adaptive Dynamics. IIASA Interim Report IR-02-054 (2002). Theoretical Population Biology 62:365-374 (2002).

No. 67 Bürger R, Gimelfarb A: Fluctuating Environments and the Role of Mutation in Maintaining Quantitative Genetic Variation. IIASA Interim Report IR-02-058 (2002). Genetical Research 80:31-46 (2002).

No. 68 Bürger R: On a Genetic Model of Intraspecific Competition and Stabilizing Selection. IIASA Interim Report IR02-062 (2002). Amer. Natur. 160:661-682 (2002).

No. 69 Doebeli M, Dieckmann U: Speciation Along Environmental Gradients. IIASA Interim Report IR-02-079 (2002). Nature 421:259-264 (2003).

No. 70 Dercole F, Irisson J, Rinaldi S: Bifurcation Analysis of a Prey-Predator Coevolution Model. IIASA Interim Report IR-02-078 (2002). SIAM Journal on Applied Mathematics 63:1378-1391 (2003).

No. 71 Le Galliard J, Ferrière R, Dieckmann U: The Adaptive Dynamics of Altruism in Spatially Heterogeneous Populations. IIASA Interim Report IR-03-006 (2003). Evolution 57:1-17 (2003).

No. 72 Taborsky B, Dieckmann U, Heino M: Unexpected Discontinuities in Life-History Evolution under SizeDependent Mortality. IIASA Interim Report IR-03-004 (2003). Proceedings of the Royal Society of London Series B 270:713-721 (2003).

No. 73 Gardmark A, Dieckmann U, Lundberg P: LifeHistory Evolution in Harvested Populations: The Role of Natural Predation. IIASA Interim Report IR-03-008 (2003). Evolutionary Ecology Research 5:239-257 (2003).

No. 74 Mizera F, Meszéna G: Spatial Niche Packing, Character Displacement and Adaptive Speciation Along an Environmental Gradient. IIASA Interim Report IR-03-062 (2003). Evolutionary Ecology Research 5:363-382 (2003).

No. 75 Dercole F: Remarks on Branching-Extinction Evolutionary Cycles. IIASA Interim Report IR-03-077 (2003). Journal of Mathematical Biology 47:569-580 (2003).

No. 76 Hofbauer J, Sigmund K: Evolutionary Game Dynamics. IIASA Interim Report IR-03-078 (2003). Bulletin of the American Mathematical Society 40:479-519 (2003).

No. 77 Ernande B, Dieckmann U, Heino M: Adaptive Changes in Harvested Populations: Plasticity and Evolution of Age and Size at Maturation. IIASA Interim Report IR03-058 (2003). Proceedings of the Royal Society of London Series B-Biological Sciences 271:415-423 (2004).

No. 78 Hanski I, Heino M: Metapopulation-Level Adaptation of Insect Host Plant Preference and Extinction-Colonization Dynamics in Heterogeneous Landscapes. IIASA Interim Report IR-03-028 (2003). Theoretical Population Biology 63:309-338 (2003).

No. 79 van Doorn G, Dieckmann U, Weissing FJ: Sympatric Speciation by Sexual Selection: A Critical Re-Evaluation. IIASA Interim Report IR-04-003 (2004). American Naturalist 163:709-725 (2004).

No. 80 Egas M, Dieckmann U, Sabelis MW: Evolution Restricts the Coexistence of Specialists and Generalists - the Role of Trade-off Structure. IIASA Interim Report IR-04-004 (2004). American Naturalist 163:518-531 (2004). 
No. 81 Ernande B, Dieckmann U: The Evolution of Phenotypic Plasticity in Spatially Structured Environments: Implications of Intraspecific Competition, Plasticity Costs, and Environmental Characteristics. IIASA Interim Report IR-04-006 (2004). Journal of Evolutionary Biology 17:613-628 (2004).

No. 82 Cressman R, Hofbauer J: Measure Dynamics on a One-Dimensional Continuous Trait Space: Theoretical Foundations for Adaptive Dynamics. IIASA Interim Report IR04-016 (2004).

No. 83 Cressman R: Dynamic Stability of the Replicator Equation with Continuous Strategy Space. IIASA Interim Report IR-04-017 (2004).

No. 84 Ravigné V, Olivieri I, Dieckmann U: Implications of Habitat Choice for Protected Polymorphisms. IIASA Interim Report IR-04-005 (2004). Evolutionary Ecology Research 6:125-145 (2004).

No. 85 Nowak MA, Sigmund K: Evolutionary Dynamics of Biological Games. IIASA Interim Report IR-04-013 (2004). Science 303:793-799 (2004).

No. 86 Vukics A, Asbóth J, Meszéna G: Speciation in Multidimensional Evolutionary Space. IIASA Interim Report IR-04-028 (2004). Physical Review 68:041-903 (2003).

No. 87 de Mazancourt C, Dieckmann U: Trade-off Geometries and Frequency-dependent Selection. IIASA Interim Report IR-04-039 (2004). American Naturalist 164:765-778 (2004).

No. 88 Cadet CR, Metz JAJ, Klinkhamer PGL: Size and the Not-So-Single Sex: Disentangling the Effects of Size on Sex Allocation. IIASA Interim Report IR-04-084 (2004). American Naturalist 164:779-792 (2004).

No. 89 Rueffler C, van Dooren TJM, Metz JAJ: Adaptive Walks on Changing Landscapes: Levins' Approach Extended. IIASA Interim Report IR-04-083 (2004). Theoretical Population Biology 65:165-178 (2004).

No. 90 de Mazancourt C, Loreau M, Dieckmann U: Understanding Mutualism When There is Adaptation to the Partner. IIASA Interim Report IR-05-016 (2005). Journal of Ecology 93:305-314 (2005).

No. 91 Dieckmann U, Doebeli M: Pluralism in Evolutionary Theory. IIASA Interim Report IR-05-017 (2005). Journal of Evolutionary Biology 18:1209-1213 (2005).

No. 92 Doebeli M, Dieckmann U, Metz JAJ, Tautz D: What We Have Also Learned: Adaptive Speciation is Theoretically Plausible. IIASA Interim Report IR-05-018 (2005). Evolution 59:691-695 (2005).

No. 93 Egas M, Sabelis MW, Dieckmann U: Evolution of Specialization and Ecological Character Displacement of Herbivores Along a Gradient of Plant Quality. IIASA Interim Report IR-05-019 (2005). Evolution 59:507-520 (2005).

No. 94 Le Galliard J, Ferrière R, Dieckmann U: Adaptive Evolution of Social Traits: Origin, Trajectories, and Correlations of Altruism and Mobility. IIASA Interim Report IR05-020 (2005). American Naturalist 165:206-224 (2005).

No. 95 Doebeli M, Dieckmann U: Adaptive Dynamics as a Mathematical Tool for Studying the Ecology of Speciation Processes. IIASA Interim Report IR-05-022 (2005). Journal of Evolutionary Biology 18:1194-1200 (2005).

No. 96 Brandt H, Sigmund K: The Logic of Reprobation: Assessment and Action Rules for Indirect Reciprocity. IIASA Interim Report IR-04-085 (2004). Journal of Theoretical Biology 231:475-486 (2004).
No. 97 Hauert C, Haiden N, Sigmund K: The Dynamics of Public Goods. IIASA Interim Report IR-04-086 (2004). Discrete and Continuous Dynamical Systems - Series B 4:575587 (2004).

No. 98 Meszéna G, Gyllenberg M, Jacobs FJA, Metz JAJ: Link Between Population Dynamics and Dynamics of Darwinian Evolution. IIASA Interim Report IR-05-026 (2005). Physical Review Letters 95:Article 078105 (2005).

No. 99 Meszéna G: Adaptive Dynamics: The Continuity Argument. IIASA Interim Report IR-05-032 (2005).

No. 100 Brännström NA, Dieckmann U: Evolutionary Dynamics of Altruism and Cheating Among Social Amoebas. IIASA Interim Report IR-05-039 (2005). Proceedings of the Royal Society London Series B 272:1609-1616 (2005).

No. 101 Meszéna G, Gyllenberg M, Pasztor L, Metz JAJ: Competitive Exclusion and Limiting Similarity: A Unified Theory. IIASA Interim Report IR-05-040 (2005).

No. 102 Szabo P, Meszéna G: Limiting Similarity Revisited. IIASA Interim Report IR-05-050 (2005).

No. 103 Krakauer DC, Sasaki A: The Greater than Two-Fold Cost of Integration for Retroviruses. IIASA Interim Report IR-05-069 (2005).

No. 104 Metz JAJ: Eight Personal Rules for Doing Science. IIASA Interim Report IR-05-073 (2005). Journal of Evolutionary Biology 18:1178-1181 (2005).

No. 105 Beltman JB, Metz JAJ: Speciation: More Likely Through a Genetic or Through a Learned Habitat Preference? IIASA Interim Report IR-05-072 (2005). Proceedings of the Royal Society of London Series B 272:1455-1463 (2005).

No. 106 Durinx M, Metz JAJ: Multi-type Branching Processes and Adaptive Dynamics of Structured Populations. IIASA Interim Report IR-05-074 (2005). Haccou P, Jager P, Vatutin V (eds): Branching Processes: Variation, Growth and Extinction of Populations, Cambridge University Press, Cambridge, UK, pp. 266-278 (2005).

No. 107 Brandt H, Sigmund K: The Good, the Bad and the Discriminator - Errors in Direct and Indirect Reciprocity. IIASA Interim Report IR-05-070 (2005). Journal of Theoretical Biology 239:183-194 (2006).

No. 108 Brandt H, Hauert C, Sigmund K: Punishing and Abstaining for Public Goods. IIASA Interim Report IR-05-071 (2005). Proceedings of the National Academy of Sciences of the United States of America 103:495-497 (2006).

No. 109 Ohtsuki A, Sasaki A: Epidemiology and DiseaseControl Under Gene-for-Gene Plant-Pathogen Interaction. IIASA Interim Report IR-05-068 (2005).

No. 110 Brandt H, Sigmund K: Indirect Reciprocity, ImageScoring, and Moral Hazard. IIASA Interim Report IR-05078 (2005). Proceedings of the National Academy of Sciences of the United States of America 102:2666-2670 (2005).

No. 111 Nowak MA, Sigmund K: Evolution of Indirect Reciprocity. IIASA Interim Report IR-05-079 (2005). Nature 437:1292-1298 (2005).

No. 112 Kamo M, Sasaki A: Evolution Towards Multi-Year Periodicity in Epidemics. IIASA Interim Report IR-05-080 (2005). Ecology Letters 8:378-385 (2005). 
No. 113 Dercole F, Ferrière R, Gragnani A, Rinaldi S: Coevolution of Slow-fast Populations: Evolutionary Sliding, Evolutionoary Pseudo-equilibria, and Complex Red Queen Dynamics. IIASA Interim Report IR-06-006 (2006). Proceedings of the Royal Society B-Biological Sciences 273:983-990 (2006).

No. 114 Dercole F: Border Collision Bifurcations in the Evolution of Mutualistic Interactions. IIASA Interim Report IR-05-083 (2005). International Journal of Bifurcation and Chaos 15:2179-2190 (2005).

No. 115 Dieckmann U, Heino M, Parvinen K: The Adaptive Dynamics of Function-Valued Traits. IIASA Interim Report IR-06-036 (2006). Journal of Theoretical Biology 241:370389 (2006).

No. 116 Dieckmann U, Metz JAJ: Surprising Evolutionary Predictions from Enhanced Ecological Realism. IIASA Interim Report IR-06-037 (2006). Theoretical Population Biology 69:263-281 (2006).

No. 117 Dieckmann U, Brännström NA, HilleRisLambers R, Ito H: The Adaptive Dynamics of Community Structure. IIASA Interim Report IR-06-038 (2006). Takeuchi Y, Iwasa Y, Sato K (eds): Mathematics for Ecology and Environmental Sciences, Springer, Berlin Heidelberg, pp. 145-177 (2007).

No. 118 Gardmark A, Dieckmann U: Disparate Maturation Adaptations to Size-dependent Mortality. IIASA Interim Report IR-06-039 (2006). Proceedings of the Royal Society London Series B 273:2185-2192 (2006).
No. 119 van Doorn G, Dieckmann U: The Long-term Evolution of Multi-locus Traits Under Frequency-dependent Disruptive Selection. IIASA Interim Report IR-06-041 (2006). Evolution 60:2226-2238 (2006).

No. 120 Doebeli M, Blok HJ, Leimar O, Dieckmann U: Multimodal Pattern Formation in Phenotype Distributions of Sexual Populations. IIASA Interim Report IR-06-046 (2006). Proceedings of the Royal Society London Series B 274:347357 (2007).

No. 121 Dunlop ES, Shuter BJ, Dieckmann U: The Demographic and Evolutionary Consequences of Selective Mortality: Predictions from an Eco-genetic Model of the Smallmouth Bass. IIASA Interim Report IR-06-060 (2006).

No. 122 Metz JAJ: Fitness. IIASA Interim Report IR-06061 (2006).

No. 123 Brandt H, Ohtsuki H, Iwasa Y, Sigmund K: A survey on indirect reciprocity. IIASA Interim Report IR-06-065 (2006). Takeuchi Y, Iwasa Y, Sato K (eds): Mathematics for Ecology and Environmental Sciences, Springer, Berlin Heidelberg, pp. 21-51 (2007).

No. 124 Dercole F, Loiacono D, Rinaldi S: Synchronization in ecological networks: A byproduct of Darwinian evolution? IIASA Interim Report IR-06-068 (2006).

Issues of the IIASA Studies in Adaptive Dynamics series can be obtained at www.iiasa.ac.at/Research/EEP/Series.html or by writing to eep@iiasa.ac.at. 


\section{Contents}

Abstract... 14 


\section{Synchronization in ecological networks:}

\section{A byproduct of Darwinian evolution?}

Fabio Dercole ${ }^{1,3}$, Daniele Loiacono ${ }^{1}$, and Sergio Rinaldi ${ }^{1,2}$

${ }^{1}$ DEI, Politecnico di Milano,

Milano, Italy

${ }^{2}$ EEP, International Institute for Applied Systems Analysis,

Laxenburg, Austria

${ }^{3}$ Corresponding author

DEI, Politecnico di Milano

Via Ponzio 34/5, 20133 Milano, Italy

Ph: +39 022399 3484; Fax: +39 0223993412

dercole@elet.polimi.it

Running title: Synchronization in ecological networks 


\begin{abstract}
The paper considers the evolution of a particular class of networks of identical chaotic oscillators, namely that of ecological networks. In these networks nodes represent patches where a certain number of plant and animal populations interact on ecological timescale, arcs represent migration flows due to dispersal, and Darwinian evolution is responsible of variations, on a longer evolutionary timescale, of the demographic parameters characterizing the populations. Up to now this problem has been mainly studied with reference to single-population patches described by one-dimensional discrete-time models and by considering only the dispersal rates of migrating populations as evolving trait. Here we propose a method of investigation which allows to study multi-population patches described by continuous-time models with evolving traits influencing various demographic parameters (including or not dispersal). The method is casted within the frame of the so-called master stability function approach for the analysis of synchronization of coupled systems, and the results obtained in a first and very simple application support the conjecture that evolution drives ecological networks toward weak forms of synchronization.
\end{abstract}

Key words: chaotic dynamics, Darwinian evolution, ecological networks, synchronization. 


\section{Introduction}

Evolution of complex networks is an important scientific problem which has already received a great deal of attention. Topological characteristics of the networks can often be interpreted, and hence predicted, as consequences of specific mechanisms governing technological and/or social evolution (see [Boccaletti et al., 2006] and references therein). A weaker form of evolution occurs when the dynamical systems associated to the nodes of the network evolve, while the structure of the network remains unchanged. This is often the case in biology, the typical example being the islands of an archipelago coupled through bird migration and populated by many species, whose characteristic traits slowly change over time in accordance with Darwinian evolution principles. In this paper we explore this class of networks and show that evolution can facilitate the emergence of collective dynamics. As for the style of the paper, we have taken the liberty of being somehow naive in the presentation of the model and in the biological interpretation of the results, as well as in the description of the mathematical technicalities. We hope that this will make the paper accessible to a broader class of readers, ranging from theoretical biologists to applied mathematicians.

Plant and animal population assemblies are rarely present in a single homogeneous area since landscapes are often spatially fragmented in various patches. Migrations between patches is often possible, in particular when they are not too far. Thus, one can properly speak of ecological networks where nodes correspond to patches and arcs to migration flows. The species associated to each node are many and each one of them is composed of one or more populations with individuals characterized by the same values of species-specific traits. Most traits are genetically determined and called adaptive. They slowly evolve through rare and small trait variations (mutations) followed by the natural selection of the best performing variants, thus allowing the species to adapt to their

environments. Species composed of one [more] population[s] are said monomorphic [polymorphic]. If the various patches of the network have similar geological and climatological characteristics, also the structure of the population assemblies associated to each node are similar.

In a great number of networks with highly diversified geographical extent and taxa, the change over time of the abundances of distant populations are highly correlated. This property, known in ecology as population synchrony, has been documented for many populations like aphids and butterflies [Hanski \& Woiwod, 1993; Sutclife et al., 1996], moths [Myers, 1998], fish [Ranta et al., 
1995a], crabs [Higgins et al., 1997], birds [Ranta et al., 1995b; Cattadori et al., 1999], voles and mice [Ims \& Steen, 1990; Bjornstad et al., 1999], hares [Ranta et al., 1995a], squirrels [Ranta et al., 1995a, 1997], lynx [Elton \& Nicholson, 1942], sheep [Grenfell et al., 1998], and others [Liebhold et al., 2004]. Figure 1A reports the most famous example, namely the yearly fur returns of Canadian lynx in five regions of Northern Canada for more than one century [Elton \& Nicholson, 1942], while Fig. 1B reports the yearly catches of male Dungeness crabs at eight locations ranging over $1000 \mathrm{~km}$ of the Pacific coastline for forty years [Higgins et al., 1997]. Both figures indicate that populations of the same species fluctuate more or less synchronously, even when they are very far.

Synchrony may arise from two independent mechanisms: (a) migration (dispersal) of populations among patches; (b) dependence of populations upon a common fluctuating environmental factor (rainfall, water temperature, ...), a mechanism known as Moran effect [Moran, 1953]. These two mechanisms are almost always present, and this has generated a large debate on their relative importance. For example, in the Canadian lynx case, only a few authors [Sinclair et al., 1993; Cazelles \& Stone, 2003] believe that the Moran effect can be the main responsible of synchronization, in particular after the discovery of a high gene flow over distances of $3000 \mathrm{~km}$ [Schwartz et al., 2002]. By contrast, in the Dungeness crab case, despite pelagic dispersal of larvae has been ascertained, [Higgins et al., 1997] showed by means of a stage-structured model that the Moran effect alone may lead to large fluctuations with multiyear cycles that seem to be locked.

Ecological networks with wild but synchronized local dynamics, like those shown in Fig. 1, are so many around the world that one is naturally brought to conjecture that this might be a consequence of species evolution. Since this conjecture [Rinaldi, 2006] is at the moment supported more by empirical evidence than by theoretical arguments, it is of great interest to reinforce it through modeling studies. This is exactly what we do in this paper by studying a prototypical eco-evolutionary model which shows that in the absence of the Moran effect the adaptive traits characterizing the populations evolve in such a way that the network tends toward the edge of synchronization. The analysis is carried out by assuming that local dynamics are chaotic in the absence of migration and that offspring inherit parental values of their characteristic adaptive traits, with possible rare and small mutations. Previous modeling studies on the evolution of ecological networks are focused on the evolution of the dispersal rates of migrating populations and often describe the local communities with simple one-dimensional discrete-time models or through 
individual-based simulations [Levin et al., 1984; McPeek \& Holt, 1996; Holt \& McPeek, 1996; Doebeli \& Ruxton, 1997; Holt, 1997; Travis \& Dytham, 1998; Johst et al., 1999; Parvinen, 1999; Harrison et al., 2001; Mathias et al., 2001; Kisdi, 2002; Murrell et al., 2002; Parvinen, 2006] (see [Parvinen, 2002; Parvinen et al., 2003] for continuous-time models). Discrete-time models easily yield asynchronous stationary dynamics (under which evolution disfavors dispersal [Hastings, 1983]) and alternative asynchronous non-stationary (cyclic or chaotic) attractors (see in particular [Holt \& McPeek, 1996; Doebeli \& Ruxton, 1997] for cases of non-stationary dynamics in the absence of Moran effect). Here we propose a general framework for the study of evolution of any adaptive trait, with possible effects on dispersal as well as on other demographic parameters, by considering a biologically more credible continuous-time model (a tritrophic food chain model) and by analyzing synchronization in details by means of the so-called master stability function approach [Pecora \& Carrol, 1998; Boccaletti et al., 2006]. Our findings are particularly in line with [Holt \& McPeek, 1996].

The paper is organized as follows. In the next section we describe a general eco-evolutionary network model and outline a method of analysis. Then in the third section we apply the method to a particularly simple network (two patches, three populations, only one dispersing population) and show that the obtained results indeed support the conjecture that evolution simplifies global behavior by enhancing the emergence of collective population dynamics. Finally, in the last section, we focus on the value as well as on the limitations of our findings and suggest studies which could further support the conjecture.

\section{Model and Methods}

\section{$2.1 \quad$ Ecological dynamics}

Consider an ecological network with $N$ patches and assume that $m$ populations with densities $n_{1}, n_{2}, \ldots, n_{m}$ characterized by various adaptive traits are present in each patch. A typical example is that of plants-herbivores-carnivores food chains leaving in well identified and homogeneous regions separated by natural or artificial barriers (e.g. rivers, mountains, motorways, ... ).

In real ecological networks the demographic parameters of the various populations slightly differ from patch to patch, due to small differences in geological and climatological conditions. This 
spatial dependence precludes complete synchronization of the network, a property which is very important for developing simple theories and obtain transparent results [Boccaletti et al., 2006]. For this reason we assume that local population dynamics are the same in all patches, i.e. that all demographic parameters are spatially independent. In other words, we assume that in the absence of migration all local population assemblies are described, on ecological time $t$, by the same $m$ differential equations (ODE's)

$$
\dot{n}(t)=f(n(t), x)
$$

where $x$ is the vector of adaptive traits, which is constant on ecological timescale, but varies on a longer evolutionary timescale, as specified below.

In the presence of migration the ecological model of the entire network is a set of $m N$ ODE's

$$
\dot{n}^{(i)}(t)=f\left(n^{(i)}(t), x\right)-\epsilon \sum_{j=1}^{N} g_{i j} D(x) n^{(j)}(t),
$$

where $n^{(i)}$ is the vector of population densities in patch $i$, the $N \times N$ matrix $G=\left[g_{i j}\right]$ identifies the network topology $\left(g_{i i}\right.$ is the number of patches connected with patch $i$, while $g_{i j}$ for $i \neq j$ is 0 if $i$ and $j$ are not connected and -1 otherwise), the $m \times m$ diagonal matrix $D=\left[D_{k}\right]$ specifies the migration flows ( $D_{k}$ is the dispersal rate of population $k$, which is zero if population $k$ does not migrate, while it is positive and possibly trait-dependent otherwise), and $\epsilon$ is a positive control parameter that scales dispersal in all migrating populations (when the discussion with respect to this factor is not of interest $\epsilon$ can be simply set to one). For example, in the case of two patches $(N=2)$, three populations $(m=3)$ and migration only in the third population, we have

$$
G=\left[\begin{array}{rr}
1 & -1 \\
-1 & 1
\end{array}\right], \quad D(x)=\left[\begin{array}{ccc}
0 & 0 & 0 \\
0 & 0 & 0 \\
0 & 0 & D_{3}(x)
\end{array}\right]
$$

In the following model (2) is called resident model because it describes the ecological dynamics of all populations in the absence of mutations.

The conditions under which the network is synchronized, i.e. the conditions under which complete synchronization $\left(n^{(i)}(t)=n^{(j)}(t)\right.$ for all $i, j$ and $\left.t\right)$ is stable, are rather complex because they 
depend upon local dynamics $(f)$, dispersal $(\epsilon D)$, and network topology $(G)$. Using the master stability function approach [Pecora \& Carrol, 1998; Boccaletti et al., 2006] the problem of synchronization can be effectively discussed by separating the information concerning network topology from the rest. More precisely, consider the largest Lyapunov exponent $L(p, x)$ of the $m$-dimensional linear time-varying system

$$
\dot{z}(t)=\left[\left.\frac{\partial}{\partial n} f(n, x)\right|_{n=n(t)}-p D(x)\right] z(t)
$$

where $n(t)$ is a solution of (1) for a generic initial condition and $p$ is a non-negative control parameter, and define the region

$$
S=\{(p, x): L(p, x) \leq 0\}
$$

in the two-dimensional space $(p, x)$. Notice that $L(0, x)$ is the largest Lyapunov exponent of system (1) which is assumed to be chaotic. Hence, $L(0, x)>0$ so that $L(p, x)$ can become negative for suitably large values of $p$ (this is guaranteed if $D(x)=I$ because in this case $L(p, x)=L(0, x)-p$ ). Then, the master stability function approach says that the network is synchronized if

$$
\left(\epsilon \lambda_{i}, x\right) \in S, \quad i=2, \ldots, m
$$

where the $\lambda_{i}$ 's are the positive eigenvalues of $G$ (notice that $\lambda_{1}=0$ because $G$ is zero-row-sum and that, if the network is connected, $\lambda_{i}>0, i=2, \ldots, m$, because $G$ is symmetric and with non-positive off-diagonal entries). For this reason region $S$ is called synchronization region. If the network cannot be desynchronized by increasing dispersal (i.e. by increasing $\epsilon$ ), then the synchronization condition (6), which involves the $(m-1)$ points $\left(\epsilon \lambda_{i}, x\right), i=2, \ldots, m$, reduces to

$$
(\epsilon \lambda, x) \in S
$$

where $\lambda$ is the smallest positive eigenvalue of $G$ (for example, $\lambda=2$ in case (3)).

If condition (7) is satisfied with $(\epsilon \lambda, x)$ on the boundary of $S$, we say that the network is on the edge of synchronization. By contrast, if point $(\epsilon \lambda, x)$ lies slightly outside $S$, there are only symptoms of synchronization which for special network topologies are revealed by interesting spatio-temporal 
patterns. Such phenomena, detectable through a thorough bifurcation analysis of model (2) in the presynchronization region $((\epsilon \lambda, x)$ outside but close to the boundary of $S)$, will not be presented here.

\subsection{Evolutionary dynamics}

From time to time, a mutation occurs in one of the populations, say in population $m$, i.e. a few individuals of population $m$ with different characteristic trait $\left(x^{\prime}\right.$ instead of $\left.x\right)$ appear in one of the patches, say in patch $i$. Thus, from that point on there are $(m+1)$ populations in patch $i$ : the $(m-1)$ resident populations $n_{1}^{(i)}, \ldots, n_{m-1}^{(i)}$, the resident population $n_{m}^{(i)}$ with trait $x$, and the mutant population $n_{m}^{\prime(i)}$ (initially very scarce) with trait $x^{\prime}$. If mutant populations migrate and the network is connected, after a short time mutant individuals are present in all patches where they interact with local resident individuals. In other words, after the appearance of a small amount of mutants somewhere in the network the ecological dynamics of all populations are described by a so-called resident-mutant model composed of $(m+1) N$ ODE's (an example of this type of models is discussed in the next section).

In agreement with general results of competition theory [Geritz et al., 2002; Geritz, 2005; Dercole $\&$ Rinaldi, 2007], if the mutant and resident populations are very similar (i.e. if $x$ and $x^{\prime}$ are very close), then generically only one of the two populations $n_{m}^{(i)}$ and $n_{m}^{\prime(i)}$ persists while the other goes extinct (of course this is true if no new mutations occur in the meantime, i.e. if mutations are rare on ecological timescale). If the mutant population goes extinct, then nothing changes in the end, since the trait value characterizing the $m$-th population is still $x$. By contrast, if the mutant population is competitively superior, it remains in the game and the resident population is ruled out. In such a case, the final consequence is the substitution of the trait value $x$ with $x^{\prime}$. In other words, the trait evolves through very small steps $\left(x \rightarrow x^{\prime}\right)$ which are taken very rarely on the ecological timescale and thus trace an evolutionary trajectory on a longer evolutionary timescale.

\subsection{Methods of analysis}

In principle one could pretend to obtain the evolutionary trajectory by solving the so-called Adaptive Dynamics canonical equation [Dieckmann \& Law, 1996], which in the present case is a first-order 
ODE of the form

$$
\frac{d}{d \tau} x(\tau)=F(x(\tau))
$$

where $\tau$ spans the evolutionary timescale. However, the analytical derivation of function $F$ in (8), is practically impossible when the dynamics over ecological time $t$ (i.e. for frozen values of the adaptive trait) of the resident model (2) are chaotic. We are therefore forced to solve the problem through repeated simulations of the resident-mutant model which reveal the sign of $F(x)$. In practice we can proceed as follows.

(i) Simulation of the resident populations before the mutation. Fix $x$ and simulate the resident model (2). Then, when system (2) is on its strange attractor, stop the simulation at a random time $t_{\text {mut }}$, called time of mutation.

(ii) Simulation of mutation. Maintaining the resident populations at the previously established values, simulate a small mutation by selecting at random a patch $i$ and a value $x^{\prime}$ close to $x$ and by assigning to the mutant population in patch $i$ a randomly generated small positive value $n_{m}^{\prime(i)}\left(t_{\mathrm{mut}}\right)$.

(iii) Simulation of resident-mutant competition. Simulate the resident-mutant model for a long time starting at $t=t_{\text {mut }}$ with the above established parameters and initial conditions.

With the exception of pathological cases, step (iii) has two possible outcomes:

1. all populations but the resident populations $n_{m}^{(j)}, j=1, \ldots, N$, persist;

2. all populations but the mutant populations $n_{m}^{\prime(j)}, j=1, \ldots, N$, persist.

If the above outcomes are robust with respect to the (randomly selected) time and amplitude of mutation, then one can say that in case n. 1 [2] the mutation $x \rightarrow x^{\prime}$ is at evolutionary advantage [disadvantage]. In other words, the process of mutation and the resident-mutant competition (i.e. Darwin's natural selection), fix unambiguously the sign of function $F$ in (8), namely the direction of evolution (for example, if $x^{\prime}>x$ and the outcome of (iii) is n. 1, then $F(x)>0$ and $x$ increases).

In conclusion, through a huge number of well organized simulations one can detect the sign of $F$ in (8) and hence obtain an evolutionary trajectory. Plotted in space $(p, x)$, evolutionary trajectories are represented by straight vertical lines with $p=\epsilon \lambda$, so that one can easily check if evolution is 
driving the network toward synchronization or not. The typical result of this analysis (confirmed by the particular application described in the next section) is that the trait converges toward a particular value $\bar{x}$ because

$$
F(x) \begin{cases}>0, & \text { for } x<\bar{x}, \\ <0, & \text { for } x>\bar{x} .\end{cases}
$$

For this reason, the value $\bar{x}$ of the adaptive trait is called evolutionary equilibrium and the conjecture is supported if point $(\epsilon \lambda, \bar{x})$ is close to the boundary of $S$.

Finally, it is worth mentioning that for pairs $\left(x, x^{\prime}\right)$ very close to $(\bar{x}, \bar{x})$ one could obtain simulation scenarios where all populations persist. This means that two very similar populations can coexist close to the equilibrium $\bar{x}$. This is a necessary (but not sufficient) condition for a monomorphic species to turn polymorphic (so-called evolutionary branching [Geritz et al., 1997, 1998]), a phenomenon which is very important in view of explaining the emergence of population diversity in ecological networks. Evolutionary branching in the evolution of dispersal has been observed in some of the above mentioned studies performed on discrete-time models [McPeek \& Holt, 1996; Holt \& McPeek, 1996; Doebeli \& Ruxton, 1997; Parvinen, 1999], but will not be investigated here.

\section{Application}

We now apply the method described in the previous section to an ecological network in which each patch is populated by a tritrophic food chain composed of resource $\left(n_{1}\right)$, consumer $\left(n_{2}\right)$, and predator $\left(n_{3}\right)$. The model we consider (see eq. (1)) is the most commonly used tritrophic food chain model [Rosenzweig \& MacArthur, 1963], namely

$$
\begin{aligned}
& \dot{n}_{1}=r n_{1}\left(1-\frac{n_{1}}{K}\right)-\frac{a_{2} n_{1}}{b_{2}+n_{1}} n_{2}, \\
& \dot{n}_{2}=e_{2} \frac{a_{2} n_{1}}{b_{2}+n_{1}} n_{2}-d_{2} n_{2}-\frac{a_{3} n_{2}}{b_{3}+n_{2}} n_{3}, \\
& \dot{n}_{3}=e_{3} \frac{a_{3} n_{2}}{b_{3}+n_{2}} n_{3}-d_{3} n_{3},
\end{aligned}
$$

where $r$ and $K$ are the net growth rate (per-capita) and carrying capacity of the resource and $a_{2}$, $b_{2}, e_{2}, d_{2}\left[a_{3}, b_{3}, e_{3}, d_{3}\right]$ are maximum predation rate, half saturation constant, efficiency, and death rate (per-capita) of consumer [predator]. This model fits our purposes because it can be chaotic 
in wide regions of parameter space [Hastings \& Powell, 1991; Kuznetsov et al., 2001]. We assume that mutations can occur only in the predator population and that the adaptive trait impacts on efficiency $e_{3}$ and dispersal $D_{3}$ (i.e. $e_{3}=e_{3}(x)$ and $D_{3}=D_{3}(x)$ ). Since an increase in dispersal is a potential advantage for the mutant [Holt \& McPeek, 1996], in order to avoid biologically trivial cases we assume that $D_{3}$ increases with $x$, while $e_{3}$ decreases. More precisely, we identify $D$ with the trait $x$ and fix the trait-dependence of $e_{3}$ as follows

$$
e_{3}(x)=\frac{e_{30}+e_{3}^{\infty} e_{31} x}{1+e_{31} x}
$$

where $e_{30}$ is the value of $e_{3}$ in the absence of migration $(x=0), e_{3}^{\infty}<e_{30}$ is the asymptotic value of $e_{3}$ corresponding to very high dispersal (for given values of all other parameters, we set $e_{3}^{\infty}$ to the value of $e_{3}$ at which model (9) ceases to be chaotic), while $e_{31}$ controls the slope of function (10).

In order to keep the computational burden under control, we limit the analysis to networks composed of two patches ( $N=2$ ), so that the matrices $G$ and $D$ appearing in the resident model (2) are given by (3). The resident-mutant model, written for $\epsilon=1$, is therefore given by the following eight ODE's

$$
\begin{aligned}
& \dot{n}_{1}^{(1)}=r n_{1}^{(1)}\left(1-\frac{n_{1}^{(1)}}{K}\right)-\frac{a_{2} n_{1}^{(1)}}{b_{2}+n_{1}^{(1)}} n_{2}^{(1)}, \\
& \dot{n}_{2}^{(1)}=e_{2} \frac{a_{2} n_{1}^{(1)}}{b_{2}+n_{1}^{(1)}} n_{2}^{(1)}-d_{2} n_{2}^{(1)}-\frac{a_{3} n_{2}^{(1)}}{b_{3}+n_{2}^{(1)}}\left(n_{3}^{(1)}+n_{3}^{\prime(1)}\right), \\
& \dot{n}_{3}^{(1)}=e_{3}(x) \frac{a_{3} n_{2}^{(1)}}{b_{3}+n_{2}^{(1)}} n_{3}^{(1)}-d_{3} n_{3}^{(1)}-x\left(n_{3}^{(1)}-n_{3}^{(2)}\right), \\
& \dot{n}_{3}^{\prime(1)}=e_{3}\left(x^{\prime}\right) \frac{a_{3} n_{2}^{(1)}}{b_{3}+n_{2}^{(1)}} n_{3}^{\prime(1)}-d_{3} n_{3}^{\prime(1)}-x^{\prime}\left(n_{3}^{\prime(1)}-n_{3}^{\prime(2)}\right), \\
& \dot{n}_{1}^{(2)}=r n_{1}^{(2)}\left(1-\frac{n_{1}^{(2)}}{K}\right)-\frac{a_{2} n_{1}^{(2)}}{b_{2}+n_{1}^{(2)}} n_{2}^{(2)}, \\
& \dot{n}_{2}^{(2)}=e_{2} \frac{a_{2} n_{1}^{(2)}}{b_{2}+n_{1}^{(2)}} n_{2}^{(2)}-d_{2} n_{2}^{(2)}-\frac{a_{3} n_{2}^{(2)}}{b_{3}+n_{2}^{(2)}}\left(n_{3}^{(2)}+n_{3}^{\prime(2)}\right), \\
& \dot{n}_{3}^{(2)}=e_{3}(x) \frac{a_{3} n_{2}^{(2)}}{b_{3}+n_{2}^{(2)}} n_{3}^{(2)}-d_{3} n_{3}^{(2)}-x\left(n_{3}^{(2)}-n_{3}^{(1)}\right), \\
& \dot{n}_{3}^{\prime(2)}=e_{3}\left(x^{\prime}\right) \frac{a_{3} n_{2}^{(2)}}{b_{3}+n_{2}^{(2)}} n_{3}^{\prime(2)}-d_{3} n_{3}^{\prime(2)}-x^{\prime}\left(n_{3}^{\prime(2)}-n_{3}^{\prime(1)}\right),
\end{aligned}
$$


where the trait values $x$ and $x^{\prime}$ are the dispersals of the resident and mutant populations, respectively. The resident model (see eq. (2)) can be immediately obtained from (11) by disregarding the two mutant equations and by annihilating the densities $n_{3}^{\prime(1)}$ and $n_{3}^{\prime(2)}$ of the mutant populations. Thus, the Lyapunov exponent $L(p, x)$ of system (4) can be computed on a grid of the space $(p, x)$ and the synchronization region $S$ (see eq. (5)) can be obtained numerically (all computations of Lyapunov exponents have been performed with the so-called standard algorithm based on Gram-Schmidt orthonormalization [Ramasubramanian \& Sriram, 2000] with adaptive time steps and convergence criterion).

The result is shown in Fig. 2 for the parameter values indicated in the caption. The most interesting property of region $S$ (shaded region in the figure) is that it is unbounded in the $p$ direction, so that eq. (7) can be used to test if the network is synchronized. Reading Fig. 2 at $p=2$ (recall that $\lambda=2$ and $\epsilon=1$ in (7)) we obtain the synchronization threshold $x^{*}$, which turns out to be $x^{*}=0.01002 \ldots$ The correlation between the predators of the two patches in the presynchronization region $\left(x<x^{*}\right)$ is shown in Figs. 3A-C for different values of $x$, while Fig. 3D shows a case of complete synchronization $\left(x>x^{*}\right)$. As expected, the correlation increases with $x$ and tends to one for $x$ approaching $x^{*}$. Of course, different parameter settings give rise to different values of the threshold $x^{*}$ and different correlations in the presynchronization region, which however are always increasing with $x$.

Now we apply the three-steps procedure outlined in the previous section. The typical simulation scenario obtained with

$$
x^{*}<x^{\prime}<x,
$$

is shown in Fig. 4. Before the time $t_{\text {mut }}$ at which the mutant are injected into the system, the two predator resident populations are equally abundant because the system is synchronized ( $x$ being larger than $x^{*}$ ). After the mutation (i.e. for $t>t_{\text {mut }}$ ) the mutant populations have a positive trend, while the resident populations decline. More precisely, in the long run the mutants substitute the residents. The same kind of scenario (outcome n. 1) has been obtained for all close by values of $x$ and $x^{\prime}$ satisfying inequality (12) and for all time $t_{\text {mut }}$ and mutant initial conditions $\left(n_{3}^{\prime(1)}\left(t_{\text {mut }}\right)\right.$ or $\left.n_{3}^{\prime(2)}\left(t_{\text {mut }}\right)\right)$. This means that above the synchronization threshold mutations decreasing the tendency to migrate of the predator are at evolutionary advantage. In other words, if for some 
reason an ecological network is synchronized, evolution tries to desynchronize it. As discussed in [Holt \& McPeek, 1996] this result is intuitively obvious. In fact, the decrease of dispersal from $x$ to $x^{\prime}$ does not imply any penalty for the mutants since dispersing and non-dispersing individuals are in any case facing the same biological and physical environment, while the corresponding increase of efficiency from $e_{3}(x)$ to $e_{3}\left(x^{\prime}\right)$ gives an advantage to mutant individuals in terms of growth rate.

The same kind of substitution is obtained for

$$
x<x^{\prime}<x^{*},
$$

when $x$ and $x^{\prime}$ are not too close to $x^{*}$ (see Fig. 5). Again the result is independent upon the time of mutation and initial densities of the mutant populations, provided $x$ and $x^{\prime}$ are sufficiently close. This means that when the network is not synchronized, mutant populations with higher dispersal can be at evolutionary advantage, even though they have a reduced efficiency. However, when inequality (13) is satisfied with $x$ and $x^{\prime}$ close to $x^{*}$, it can also happen that the mutant populations do not survive in the long run (outcome n. 2). Also this result can be justified intuitively. In fact, if $x$ and $x^{\prime}$ in (13) are close to $x^{*}$, the populations are highly correlated, though they are not completely synchronized, so that any individual after migration is facing almost the same biological and physical environment than before migration. This implies that the advantages due to migration are modest while the disadvantages due to the drop of efficiency can be more conspicuous.

By repeating the above simulations for many different pairs $\left(x, x^{\prime}\right)$ we have obtained the evolutionary trajectory (straight vertical line in Fig. 2) and an accurate estimate of the evolutionary equilibrium $\bar{x}$. Figure 2 clearly points out that the evolutionary equilibrium is close to the edge of synchronization. In other words, evolution has the power to desynchronize synchronous ecological networks (upper segment of the trajectory ending at $x=\bar{x}$ ), but at the same time it has the power of driving asynchronous networks toward the edge of synchronization (lower segment of the trajectory). This result, which is fully justifiable on a purely intuitive basis, is more precise than that of [Holt \& McPeek, 1996] who erroneously concluded that higher dispersals are always at evolutionary advantage if local ecological dynamics are chaotic and asynchronous. At the same time, our result is also more transparent than that of [Doebeli \& Ruxton, 1997] who found sophisticated evolutionary dynamics of dispersal by relying, however, on a resident model with a rather complex 
bifurcation structure involving coexisting synchronous and asynchronous attractors.

How close the evolutionary equilibrium $\bar{x}$ is to the synchronization threshold $x^{*}$ and how correlated the predator populations are at the evolutionary equilibrium, obviously has to do with how severe is the drop in efficiency caused by increasing dispersal. This is controlled by the parameter $e_{31}$ in eq. (10), which measures marginal efficiency. Figure 6 summarizes the results obtained by repeating all the above numerical experiments for different marginal efficiencies.

\section{Conclusions}

A particular but important class of evolving networks, namely ecological networks, has been analyzed in this paper. In such networks nodes represent patches where a certain number of plant and animal populations dynamically interact and arcs represent migration flows due to dispersal. Within this context there are, in general, two separated timescales of interest dealing, respectively, with ecology (fast dynamics) and evolution (slow dynamics). Observations on ecological timescale reveal that a great number of networks around the world have rather wild local dynamics which are, however, at least weakly synchronized. It is therefore quite natural to conjecture [Rinaldi, $2006]$ that these two properties are a long-term byproduct of evolution.

In this paper we have given a formal support to the above conjecture by studying the evolution of a very simple network with only two nodes and a tritrophic food chain composed of resource, consumer, and predator populations associated to each node. The model is more complex and realistic than previously considered models [Holt \& McPeek, 1996; Doebeli \& Ruxton, 1997]. Following a standard approach which is justified when mutations are small and rare, and restricting the analysis to the case in which only the predator population can mutate, we have shown through a huge number of suitably organized simulations that evolution is responsible of very slow trends in demographic and dispersal parameters which drive the network toward weak forms of synchronization. In other words, given that local ecological dynamics are chaotic (first part of the conjecture), it looks like evolution is indeed capable of slowly modifying the demographies in such a way that weak forms of collective dynamics emerge (second part of the conjecture).

The merit of this paper is to have shown that it is possible to support a fascinating conjecture concerning the role of Darwinian evolution through a formal approach melting together for the first 
time the theory of Adaptive Dynamics [Dieckmann \& Law, 1996; Metz et al., 1996; Geritz et al., 1997, 1998] (see also [Dercole \& Rinaldi, 2007]) and the theory of network synchronization [Pecora \& Carrol, 1998; Pikovsky et al., 2001; Boccaletti et al., 2006]. However, the specific application discussed in this paper is extremely simplified with respect to reality, so that other studies of the same kind are needed to further support the conjecture. First of all one could check if the obtained results remain valid for more realistic models taking into account phenomena like predator cooperation, antipredator behavior, predator harvesting, as well as others. This seems to be possible by applying the same general method of analysis proposed in this paper. Conceptually more difficult would be variants concerning migration flows depending upon the abundances of prey or predators of the dispersing population (active dispersal). Also the extension to networks with physically diversified nodes would be of interest because this is always the case in real world. But this variant is far from being trivial because spatial heterogeneity gives more room to species polymorphism. Finally, it is worth noticing that in the present paper we have completely ruled out the Moran effect, which is always present in real ecological networks where close patches are characterized by very similar climatological and meteorological variabilities. This means that in order to better support the conjecture the theoretical studies we have just suggested should also be performed by substituting the dispersal mechanism with the Moran effect or by considering both of them at the same time (see e.g. [McPeek \& Holt, 1996; Johst et al., 1999]). 


\section{References}

Bjornstad, O. N., Stenseth, N. C. \& Saitoh, T. [1999] "Synchrony and scaling in dynamics of voles and mice in northern japan," Economica 80, 622-637.

Boccaletti, S., Latora, V., Moreno, Y., Chabez, M. \& Hwang, D.-U. [2006] "Complex networks: Structure and dynamics," Physics Reports 424, 175-308.

Cattadori, I. M., Hudson, P. J., Merler, S. \& Rizzoli, A. [1999] "Synchrony, scale and temporal dynamics of rock bartridge (Alectrois graeca saxatalis) populations in the dolomites," Journal of Animal Ecology 68, 540-549.

Cazelles, B. \& Stone, L. S. [2003] "Detection of imperfect population synchrony in an uncertain world," Journal of Animal Ecology 72, 953-968.

Dercole, F. \& Rinaldi, S. [2007] Analysis of Evolutionary Processes: The Adaptive Dynamics Approach and its Applications (Princeton University Press, Princeton, NJ), (forthcoming).

Dieckmann, U. \& Law, R. [1996] "The dynamical theory of coevolution: A derivation from stochastic ecological processes," Journal of Mathematical Biology 34, 579-612.

Doebeli, M. \& Ruxton, G. D. [1997] "Evolution of dispersal rates in metapopulation models: Branching and cyclic dynamics in phenotype space," Evolution 51, 1730-1741.

Elton, C. S. \& Nicholson, M. [1942] "The ten-year cycle in numbers of the lynx in canada," Journal of Animal Ecology 11, 215-244.

Geritz, S. A. H. [2005] "Resident-invader dynamics and the coexistence of similar strategies," Journal of Mathematical Biology 50, 67-82.

Geritz, S. A. H., Gyllenberg, M., Jacobs, F. J. A. \& Parvinen, K. [2002] "Invasion dynamics and attractor inheritance," Journal of Mathematical Biology 44, 548-560.

Geritz, S. A. H., Kisdi, E., Meszéna, G. \& Metz, J. A. J. [1998] "Evolutionarily singular strategies and the adaptive growth and branching of the evolutionary tree," Evolutionary Ecology 12, $35-57$. 
Geritz, S. A. H., Metz, J. A. J., Kisdi, E. \& Meszéna, G. [1997] "The dynamics of adaptation and evolutionary branching," Physical Review Letters 78, 2024-2027.

Grenfell, B. T., Wilson, K. \& et al., B. F. F. [1998] "Noise and determinism in synchronized sheep dynamics," Nature 394, 674-677.

Hanski, I. \& Woiwod, I. P. [1993] "Spatial synchrony in the dynamics of moth and aphid populations," Journal of Animal Ecology 62, 656-668.

Harrison, M. A., Lai, Y.-C. \& Holt, R. D. [2001] "Dynamical mechanism for coexistence of dispersing species," Journal of Theoretical Biology 213, 53-72.

Hastings, A. [1983] "Can spatial variation alone lead to selection for dispersal?" Theoretical Population Biology 24, 244-251.

Hastings, A. \& Powell, T. [1991] "Chaos in a three species food chain," Economica 72, 896-903.

Higgins, K., Hastings, A., Sarvela, J. N. \& 1. W. Bostford [1997] "Stochastic dynamics and deterministic skeletons: population behavior of dungeness crab," Science 276, 1431-1435.

Holt, R. D. [1997] "On the evolutionary stability of sink populations," Evolutionary Ecology 11, $723-732$.

Holt, R. D. \& McPeek, M. A. [1996] "Chaotic population dynamics favors the evolution of dispersal," The American Naturalist 148, 709-718.

Ims, R. A. \& Steen, H. [1990] "Geographical synchrony in microtine rodent populations: a theoretical explanation of the role of nomadic avian predators," Oikos 57, 381-387.

Johst, K., Doebeli, M. \& Brandl, R. [1999] "Evolution of complex dynamics in spatially structured populations," Proceedings of the Royal Society of London B 266, 1147-1154.

Kisdi, E. [2002] "Dispersal: Risk spreading versus local adaptation," The American Naturalist 159, $579-596$.

Kuznetsov, Yu. A., De Feo, O. \& Rinaldi, S. [2001] "Belyakov homoclinic bifurcations in a tritrophic food chain model," SIAM Journal on Applied Mathematics 62, 462-487. 
Levin, S. A., Cohen, D. \& Hastings, A. [1984] "Dispersal strategies in patchy environments," Theoretical Population Biology 26, 165-191.

Liebhold, A. M., Koenig, W. D. \& Bjørnstad, O. N. [2004] "Spatial synchrony in population dynamics," Annual Review of Ecology, Evolution and Systematics 35, 467-490.

Mathias, A., Kisdi, E. \& Olivieri, I. [2001] "Divergent evolution of dispersal in a heterogeneous landscape," Evolution 55, 246-259.

McPeek, M. A. \& Holt, R. D. [1996] "The evolution of dispersal in spatially and temporally varying environments," The American Naturalist 140, 1010-1027.

Metz, J. A. J., Geritz, S. A. H., Meszéna, G., Jacobs, F. J. A. \& van Heerwaarden, J. S. [1996] "Adaptive dynamics: A geometrical study of the consequences of nearly faithful reproduction," in "Stochastic and Spatial Structures of Dynamical Systems," eds. van Strien, S. J. \& Verduyn Lunel, S. M. (Elsevier Science, Burlington, MA), pp. 183-231.

Moran, P. A. P. [1953] "The statistical analysis of the canadia lynx cycle. II. Synchronisation and meteorology," Australian Journal of Zoology 1, 291-298.

Murrell, D. J., Travis, J. M. J. \& Dytham, C. [2002] "The evolution of dispersal distance in spatially-structured populations," Oikos 97, 229-236.

Myers, J. H. [1998] "Synchrony in outbreaks of forest lepidoptera: a possible example of the Moran effect," Economica 79, 1111-1117.

Parvinen, K. [1999] "Evolution of migration in a metapopulation," Bulletin of Mathematical Biology 61, 531-550.

Parvinen, K. [2002] "Evolutionary branching of dispersal strategies in structured metapopulations," Journal of Mathematical Biology 45, 106-124.

Parvinen, K. [2006] "Evolution of dispersal in a structured metapopulation model in discrete time," Bulletin of Mathematical Biology 68, 655-678. 
Parvinen, K., Dieckmann, U., Gyllenberg, M. \& Metz, J. [2003] "Evolution of dispersal in metapopulations with local density dependence and demographic stochasticity," Journal of Evolutionary Biology 16, 143-153.

Pecora, L. M. \& Carrol, T. L. [1998] "Master stability functions for synchronized coupled systems," Physical Review Letters 10, 2109-2112.

Pikovsky, A., Rosenblum, M. \& Kurths, J. [2001] Synchronization (Cambridge University Press, Cambridge).

Ramasubramanian, K. \& Sriram, M. S. [2000] "A comparative study of computation of Lyapunov spectra with different algorithms," Physica D 139, 72-86.

Ranta, E., Kaitala, V., Lindström, J. \& Helle, E. [1997] "The Moran effect and synchrony in population dynamics," Oikos 78, 136-142.

Ranta, E., Kaitala, V., lindström, J. \& Lindén, H. [1995a] "Synchrony in population dynamics," Proceedings of the Royal Society of London B 262, 113-118.

Ranta, E., Lindström, J. \& Lindén, H. [1995b] "Synchrony in tetraonid population dynamics," Journal of Animal Ecology 64, 756-776.

Rinaldi, S. [2006] "Locally complex and globally simple: the goal of evolution in biological networks," Plenary lecture at NOLTA 2006, Bologna, Italy, September 11-14, 2006.

Rosenzweig, M. L. \& MacArthur, R. H. [1963] "Graphical representation and stability conditions of predator-prey interactions," The American Naturalist 97, 209-223.

Schwartz, M. K., Mills, L. S., McKelvey, K. S., Ruggiero, L. F. \& Allendorf, F. W. [2002] "DNA reveals high dispersal synchronizing the population dynamics of Canada lynx," Nature 415, $520-522$.

Sinclair, A. R. E., Goseline, J. M., Holdsworth, G., Krebs, C. J., Boutin, S., Smith, N. M., Boonstra, R. \& Dale, M. [1993] "Can the solar cycle and climate synchronize the snowshoe hare cycle in Canada? evidence from tree rings and ice cores," The American Naturalist 141, 173-198. 
Sutclife, O. L., Thomas, C. D. \& Moss, D. [1996] "Spatial synchrony and asynchrony in butterfly populations dynamics," Journal of Animal Ecology 65, 85-95.

Travis, J. M. J. \& Dytham, C. [1998] "The evolution of dispersal in a metapopulation: a spatially explicit, individual-based model," Proceedings of the Royal Society of London B 265, 17-23. 


\section{Figure captions}

\section{Figure 1}

(A) Lynx fur returns in five regions of Northern Canada (reproduced from [Elton \& Nicholson, 1942]). (B) Dungeness crabs catches $\left(\times 10^{3} \mathrm{Kg}\right)$ at eight locations of the Pacific coast (reproduced from [Higgins et al., 1997]).

\section{Figure 2}

The synchronization region $S$ (shaded region) and the evolutionary trajectory (thick line with $p=2$ ). Evolutionary equilibrium: $\bar{x}=0.00961 \ldots$ (see Fig. $3 \mathrm{C}$ for the corresponding predator correlation in the two patches); synchronization threshold $x^{*}=0.01002 \ldots$ Parameter values: $r=$ $1.2, K=1.1, a_{2}=5, a_{3}=0.1, h_{2}=0.6, h_{3}=20, d_{2}=0.4, d_{3}=0.01, e_{2}=1, e_{30}=1, e_{31}=0.1$, $e_{3}^{\infty}=0.8118$.

\section{Figure 3}

Correlation between the predator populations $n_{3}^{(1)}$ and $n_{3}^{(2)}$ in the two patches in the absence of mutants. Panels A-D show the attractor projection in the plane $\left(n_{3}^{(1)}, n_{3}^{(2)}\right)$ for different values of the adaptive trait $x\left(\mathrm{~A}-\mathrm{C}\right.$ in the presynchronization region $\left(x<x^{*}\right), \mathrm{D}$ in the synchronization region $\left.\left(x>x^{*}\right)\right)$ and report the corresponding values of the correlation index $\rho(x)$. Complete synchronization $(\rho(x)=1)$ is represented by the diagonal of the plane $\left(n_{3}^{(1)}, n_{3}^{(2)}\right)$ (dotted line). Parameter values as in Fig. 2.

\section{Figure 4}

Typical simulation scenario for $x^{*}<x^{\prime}<x$. The two mutant (less dispersive) predator populations (in blue) are at evolutionary advantage and substitute the resident (more dispersive) predator populations (in red). Panels $\mathrm{A}$ and $\mathrm{C}$ show that the resident and mutant predator populations are synchronous before the mutation (panel A) and after the substitution (panel C). Panel B shows that the mutation occurs in patch 1 and that the mutant populations quickly synchronize. Adaptive traits: $x=0.015, x^{\prime}=0.011$. Parameter values as in Fig. 2 . 


\section{Figure 5}

Typical simulation scenario for $x<x^{\prime}<x^{*}$. The two mutant (more dispersive) predator populations (in blue) are at evolutionary advantage and substitute the resident (less dispersive) predator populations (in red). Panels $\mathrm{A}$ and $\mathrm{C}$ show that the resident and mutant predator populations are asynchronous before the mutation (panel A) and after the substitution (panel C). Panel B shows that the mutation occurs in patch 1 and that the mutant populations remain asynchronous. Adaptive traits $x=0.004, x^{\prime}=0.008$. Parameter values as in Fig. 2.

\section{Figure 6}

Influence of marginal efficiencies $e_{31}$ on evolutionary equilibrium $\bar{x}$ and synchronization threshold $x^{*}$ (panel A) and on predator correlation $\rho(\bar{x})$ in the two patches at evolutionary equilibrium (panel B). 


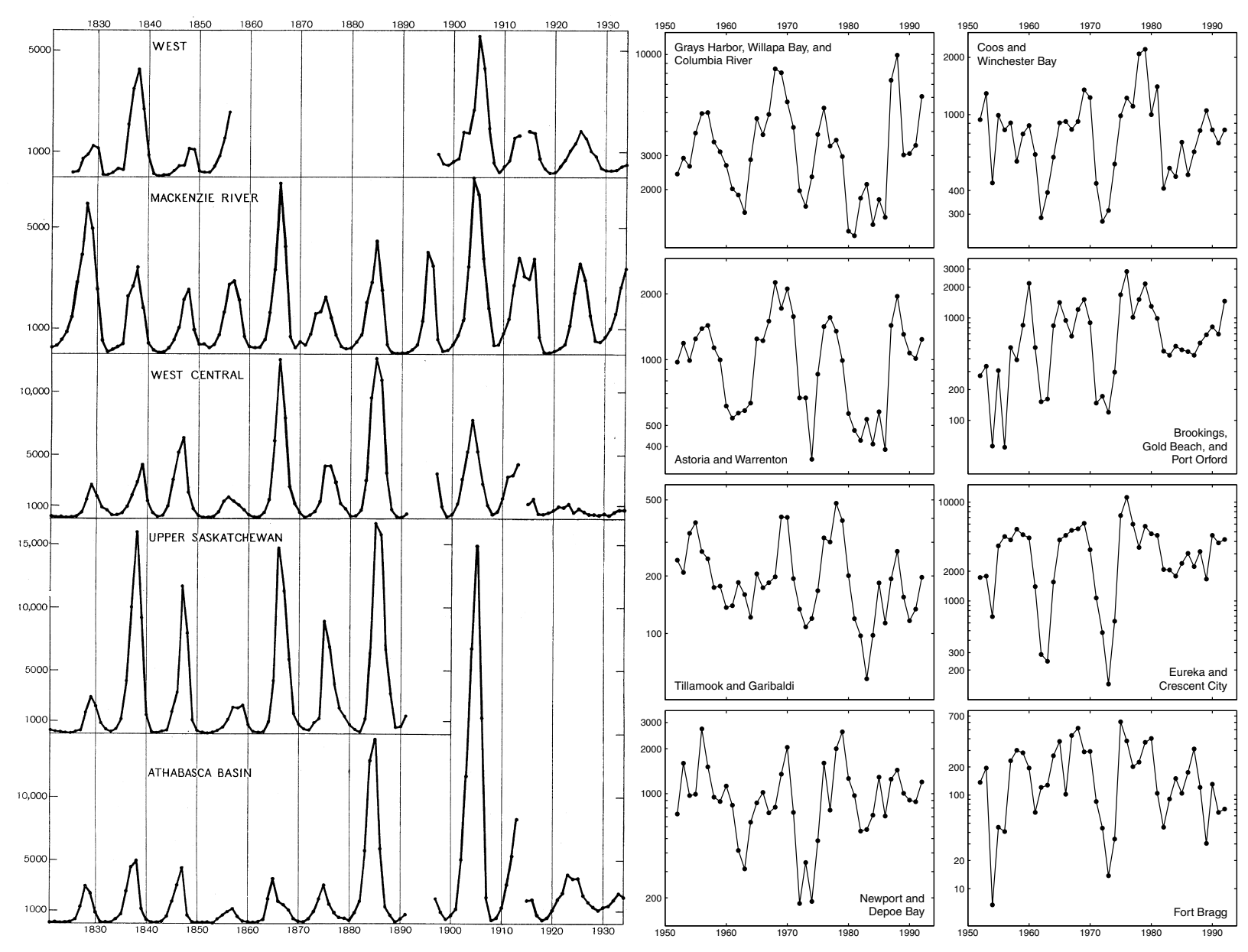

(A)

(B)

Figure 1 


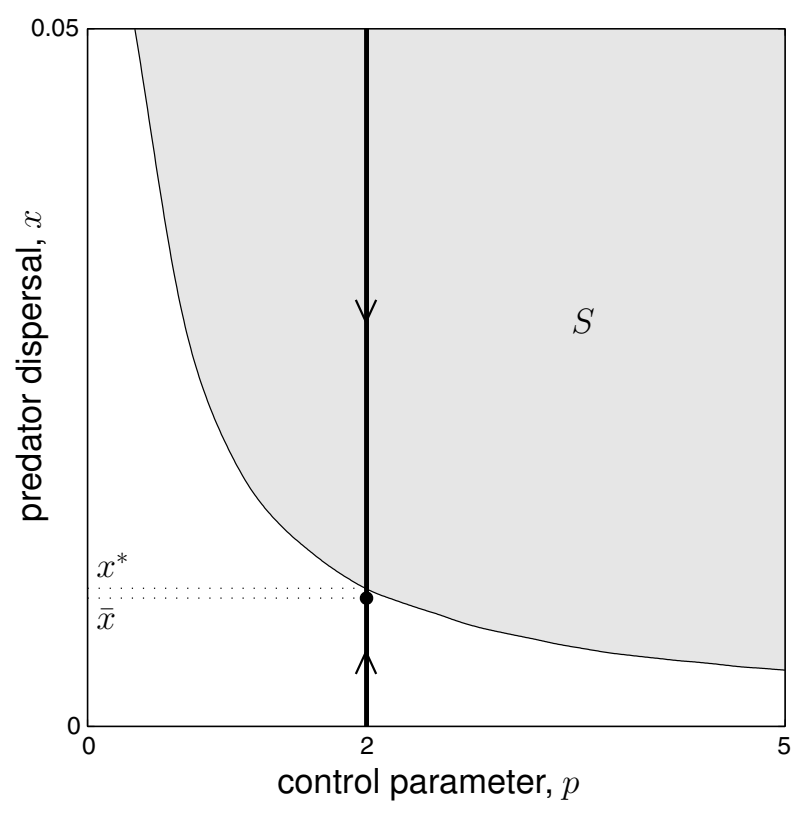

Figure 2

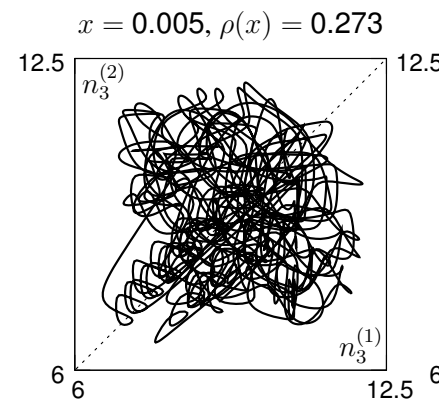

(A)

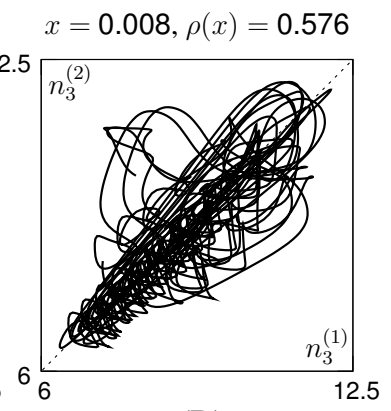

(B)

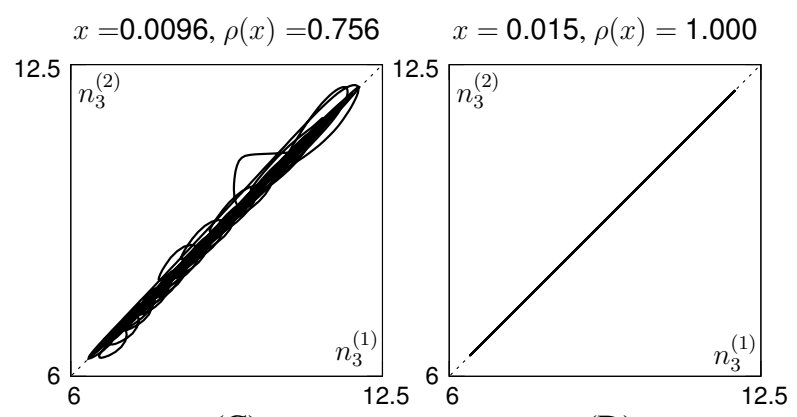

(C)

(D)

Figure 3 

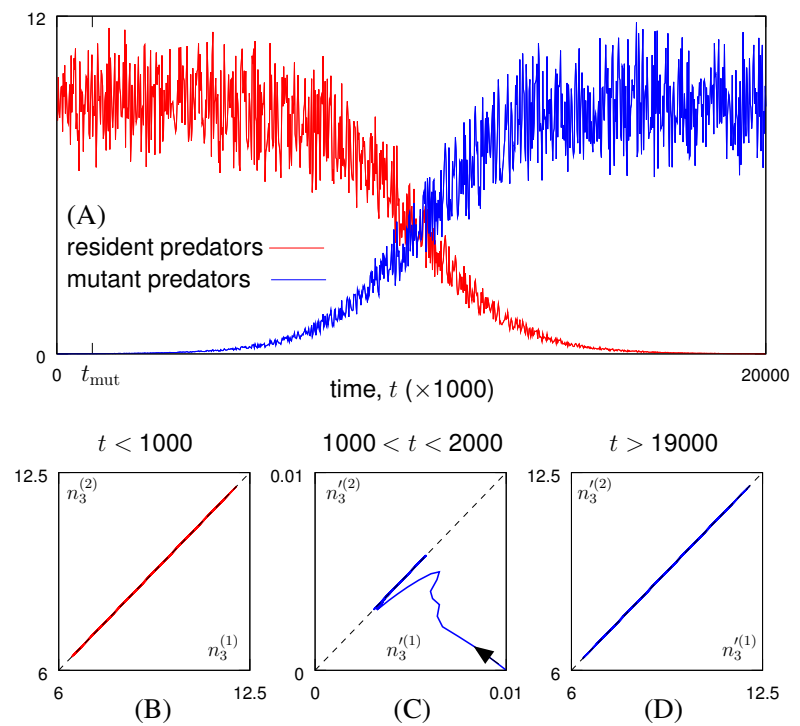

Figure 4

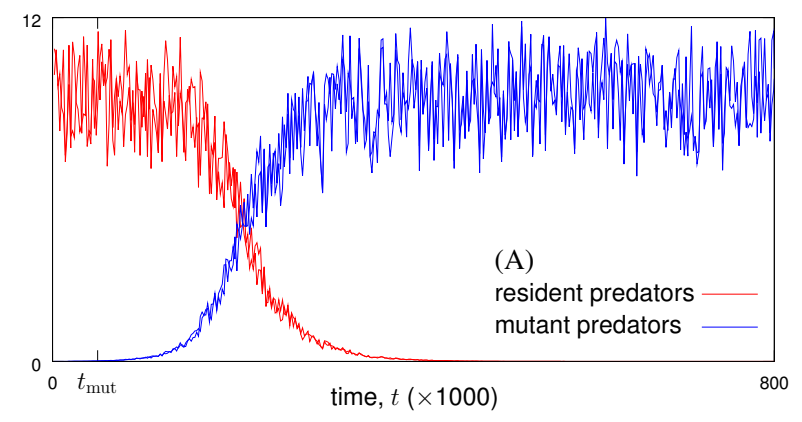

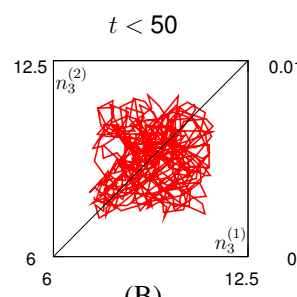

(B)

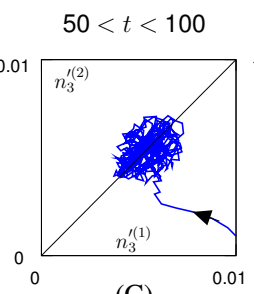

(C)

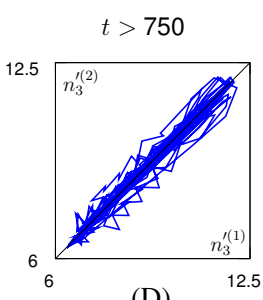

(D)

Figure 5 

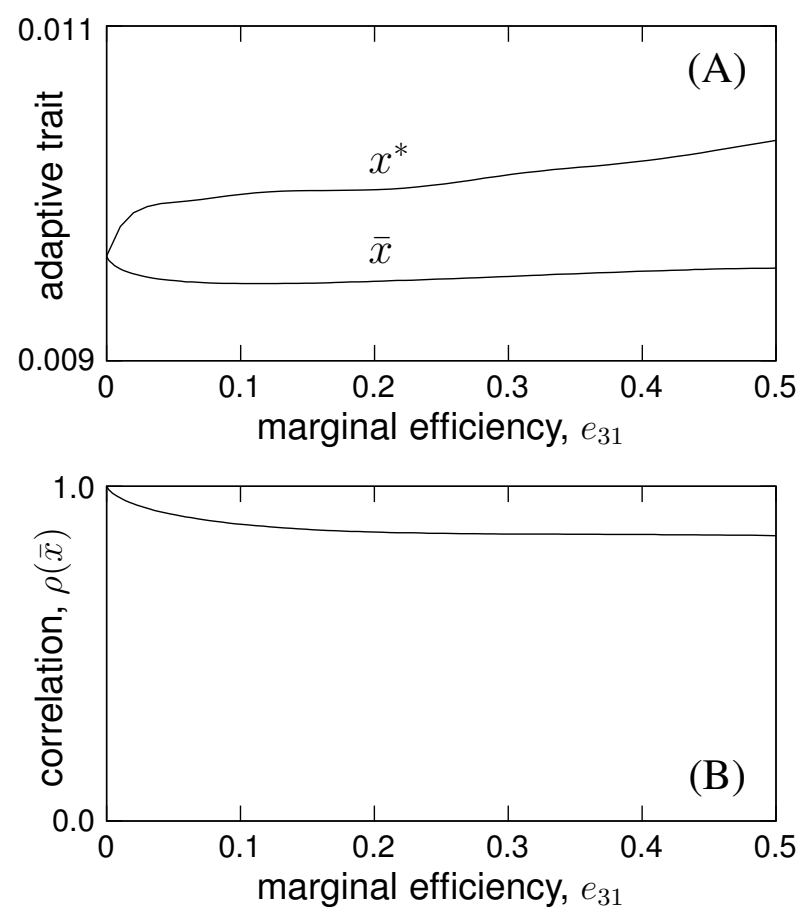

Figure 6 